\title{
Sexual Orientation Enumeration in State Antibullying Statutes in the United States: Associations with Bullying, Suicidal Ideation, and Suicide Attempts Among Youth
}

\author{
Ilan H. Meyer, PhD, ${ }^{1}$ Feijun Luo, PhD, ${ }^{2}$ Bianca D.M. Wilson, PhD, ${ }^{1}$ and Deborah M. Stone, ScD, MSW, MPH ${ }^{3}$
}

\begin{abstract}
Purpose: The aim was to assess the associations of antibullying U.S. state statutes that enumerate sexual orientation with exposure to bullying and other stressors and with suicidal ideation and suicide attempts in sexual minority and non sexual minority youth.

Methods: We analyzed data from the 2015 national school-based Youth Risk Behavior Survey, representative of 9th through 12th grade students attending public and private schools in the United States. We reviewed each state's antibullying statutes and classified them on enumeration.

Results: Antibullying state laws that enumerate sexual orientation were associated with lower risk for suicide attempts and serious attempts requiring medical attention and lower risk for forced sexual intercourse. They were also associated with feeling safe at school or on the way to or from school. Results did not differ by sexual orientation.

Conclusions: Enumeration of sexual orientation was associated with reduced stressors and suicide attempts, but it is insufficient to remove significant disparities based on sexual orientation. Additional policies and practices are required to address persistent sexual orientation disparities in exposure to bullying and suicidal behavior.
\end{abstract}

Keywords: bullying, law and policy, schools, sexual minority youth, suicide attempts

\section{Introduction}

$\mathbf{H}$ OMOPHOBIC AND TRANSPHOBIC VIOLENCE, including bullying, is a challenge for educators and policy makers internationally as shown by data from Africa, Asia, Europe, Latin America and the Caribbean, North America, and the Pacific. ${ }^{1}$ The United States has some of the highest rates of homophobic and transphobic violence. ${ }^{1}$ Bullying has been identified as a particular challenge in U.S. schools and is associated with suicide risk factors, including physical and sexual violence, feeling unsafe, depression, thoughts of suicide, and suicidal behavior. ${ }^{2-4}$ A comprehensive report by the United Nations Educational, Scientific and Cultural Organization recommended a variety of policy approaches to address homophobic and transphobic violence. ${ }^{1}$ For example, a study in Australia has shown that sexual and gender minority students' perceptions of policies that protect them were associated with increased sense of safety and reduced likeli- hood of thinking about self-harm, actual self-harm, suicidal ideation, and attempted suicide. ${ }^{5}$

In the United States, by 2015, all 50 states and the District of Columbia enacted laws aimed at reducing bullying. ${ }^{6}$ However, little research has tested the effectiveness of state antibullying policies in reducing bullying and its ill effects; the research that is available has shown mixed results. One study found lower odds of reported bullying behavior in states that were compliant with U.S. Department of Education guidelines, such as having a clearly defined scope of the law and stated requirements for districts to implement local policies. ${ }^{7}$ However, in another study of bullying prevalence in Iowa, researchers found no reduction from before to 3 years after the enactment of the antibullying law. ${ }^{8}$

Sexual and gender minorities are particularly targeted for bullying and suffer its negative effects, including increased risk for suicidal ideation and behavior. ${ }^{9-11}$ In $2015,34 \%$ of lesbian, gay, and bisexual (LGB) students had been bullied

\footnotetext{
${ }^{1}$ The Williams Institute, School of Law, University of California Los Angeles, Los Angeles, California.

Divisions of ${ }^{2}$ Analysis, Research, and Practice Integration, ${ }^{3}$ Violence Prevention, National Center for Injury Prevention and Control, Centers for Disease Control and Prevention, Atlanta, Georgia.
} 
at school over a year, compared with $19 \%$ of heterosexual students. During this same time frame, $28 \%$ of LGB students reported online bullying, compared with $14 \%$ of heterosexual students; $43 \%$ had seriously considered attempting suicide, and $29 \%$ had attempted suicide, compared with $15 \%$ and $6 \%$, respectively, of heterosexual students. ${ }^{9}$

Advocates recommend that laws specifically enumerate sexual orientation and gender identity-that is, specifically list these categories in the statute. The argument is that enumeration would impel school personnel to address these specific forms of bullying, which can be otherwise ignored even in the presence of a general anti-bullying law. ${ }^{12-15}$ In one study, researchers assessed the role of sexual orientation enumeration in Oregon school districts and found that counties with more school districts that enumerated sexual orientation in their antibullying policies had the lowest rates of suicide attempts among lesbian and gay (but not bisexual) youth. ${ }^{16}$

To fill the gap in understanding the effectiveness of enumerated antibullying laws, we assess whether youth in states that have such enumerated sexual orientation antibullying statutes are exposed to fewer experiences of bullying and other stressors at school and have less suicidal ideation and fewer suicide attempts compared with youth in states whose antibullying statutes do not enumerate sexual orientation. ${ }^{17}$ We further assess whether such an association, if it exists, is specific to sexual minority youth or whether it is generalized across all students, regardless of sexual orientation.

\section{Methods}

\section{Sample}

The national Youth Risk Behavior Survey (YRBS) is a school-based survey conducted by the Centers for Disease Control and Prevention biannually. ${ }^{18}$ Survey responses are representative of 9 th through 12 th grade students attending public and private schools in the United States. Although schools in all 50 states and the District of Columbia are included in the sampling frame, because the survey uses a three-stage cluster sample design, not all states have schools drawn into the sample. ${ }^{9}$ The 2015 national YRBS sample included 15,624 respondents from 27 states. More detailed information about YRBS sampling and weighting is available elsewhere. ${ }^{9}$ The study was exempt from institutional review board review as the analyses involved a deidentified data set that is available publicly.

\section{Measures}

Sexual minority status. We defined sexual minority youth based on responses to two items: sexual identity and sexual contact. Youth who endorsed being "gay or lesbian," "bisexual," or "not sure" or who reported that they had any same-sex sexual contact during their lifetime were classified as sexual minority youth. Youth not classified as sexual minority were classified as non sexual minority youth. Sexual minority status was missing if sexual identity was missing and sexual contact was missing or none $(N=882)$.

Enumerated antibullying law. States were coded as to whether by 2015 they did or did not have an antibullying statute that enumerated sexual orientation. A statute was considered to enumerate sexual orientation if the statute listed sexual orientation specifically as a focus of the law (Supplementary Table S1; Supplementary Data are available online at www.liebertpub.com/lgbt).

Experienced bullying and related stressors. Two items assessed bullying, asking whether respondents were "bullied" on school property and "electronically bullied." We also assessed five stressful experiences and indicators of victimization: felt unsafe at school or on their way to or from school in the past 30 days; threatened or injured with a weapon such as a gun, knife, or club on school property; in a physical fight; injured and had to be treated by a doctor or nurse after being in a physical fight; and ever physically forced to have sexual intercourse. All responses were dichotomized as "yes," if the outcome occurred, or "no," if the outcome never occurred.

Suicidal ideation and suicide attempts. Respondents answered the following four items related to the year before the interview: seriously considered attempting suicide; made a plan for attempting suicide; actually attempted suicide; and made an attempt that resulted in an injury, poisoning, or overdose that had to be treated by a doctor or nurse. Responses were dichotomized as "yes," if this occurred, or "no," if it never occurred.

Demographic characteristics. Sex (male or female), grade in school $(9,10,11$, or 12$)$, and race/ethnicity (categorized as non-Hispanic American Indian/Alaska Native, Asian, Black or African American, Native Hawaiian/other Pacific Islander, or White; or Hispanic/Latino or nonHispanic multiple races or Hispanic multiple races) were self-reported by respondents.

\section{Data analysis}

We calculated frequencies to describe the sample and conducted logistic regression to test whether antibullying laws that enumerated sexual orientation were associated with reduced bullying, related stressors, and suicidal ideation and suicide attempts, controlling for demographic characteristics. We calculated odds ratios and $95 \%$ confidence intervals for youth attending schools in a state with enumerated antibullying statutes compared with youth attending schools in states that do not have such enumeration, across all respondents, as well as among sexual minority youth compared with non sexual minority youth, across all states. We also tested interactions to assess whether the associations between enumerated antibullying state laws and bullying and other stressors and suicidal ideation and suicide attempts differed based on sexual minority status.

We used SAS software version 9.3 (SAS Institute Inc., Cary, NC) with survey procedures in all statistical analyses to account for the complex sampling design of the YRBS. ${ }^{19}$ Missing data were handled using the SAS survey procedure option NOMCAR (not missing completely at random). ${ }^{20} \mathrm{~A}$ weight based on student sex, race/ethnicity, and grade was applied to each record to adjust for school and student nonresponse and oversampling of Black and Hispanic students. The overall weights were scaled so that the weighted count of students equals the total sample size, and the weighted proportions of students in each grade match the national population proportions. Therefore, weighted estimates are 
representative of all students in grades 9-12 attending public and private schools in the United States. ${ }^{9}$

\section{Results}

The 2015 national YRBS sample included 15,624 respondents from 27 states, in which 12 states had an antibullying statue that enumerated sexual orientation and 15 states did not (Supplementary Table S1). The weighted percentages of male and female students were $51.3 \%$ and $48.7 \%$, respectively, and percentages of 9 th, 10th, 11th, and 12th grade students were $27.2 \%, 25.7 \%, 23.9 \%$, and $23.1 \%$, respectively. White, Black/African American, multiple-Hispanic, and Hispanic/Latino were the leading four race/ethnicity categories, with weighted percentages of $54.5 \%, 13.6 \%, 12.3 \%$, and $9.9 \%$, respectively.

Nationwide, $12.8 \%$ (standard error $[\mathrm{SE}]=0.8 \%$ ) of students met this study's definition of sexual minority youth. Sexual minority youth were more likely than non sexual minority youth to be female $(68.8 \%$ vs. $45.7 \%$, Rao-Scott chi square $\left[\mathrm{Q}_{\mathrm{RS}}\right]=74.6[1], p<0.001$ ), and were more likely to be Black/African American (16.9\% vs. $13.1 \%, \mathrm{Q}_{\mathrm{RS}}=5.7$ [1] $p=0.017)$. Sexual minority youth were less likely than non sexual minority youth to be White $\left(48.0 \%\right.$ vs. $55.5 \%, \mathrm{Q}_{\mathrm{RS}}=6.5[1]$ $p=0.011$ ) and more likely to have multiple race/ethnicities (both Hispanic and non-Hispanic, $14.7 \%$ vs. $12.1 \%, \mathrm{Q}_{\mathrm{RS}}=5.8$ [1] $p=0.015$ and $6.8 \%$ vs. $4.2 \%, \mathrm{Q}_{\mathrm{RS}}=16.7[1] p<0.001$, respectively). Sexual minority and non sexual minority youth did not differ in the grade they attended in school.

Table 1 shows bullying and other stressors and suicidal ideation and suicide attempts among youth by antibullying law (sexual orientation enumerated vs. not enumerated) and youth sexual orientation (sexual minority vs. non sexual minority). First, across all respondents, regardless of sexual orientation, and controlling for sex, grade, and race/ethnicity, having an antibullying state law that enumerates sexual orientation was associated with reduced odds of bullying, stressors, and suicidal ideation and suicide attempts (Table 1, Column C). Related to stressors, the relationship was significant for feeling unsafe at school or on the way to or from school and ever having been physically forced to have sexual intercourse. Related to suicidal ideation and suicide attempts outcomes, the association was significant for attempting suicide and making a suicide attempt that required being treated by a doctor or nurse.

Second, across all states, compared with non sexual minority youth, more sexual minority youth experienced each of the bullying and other stressors we examined and they were more likely than non sexual minority youth to have suicidal ideation and suicide attempts (Table 1, Column D).

A test of the interaction between sexual minority status and the presence of an enumerated antibullying state law was not significant for any of the outcomes we examined, suggesting that the effect of enumerated state laws on bullying, stressors, and suicide was similar for sexual minority and non sexual minority youth (not shown).

\section{Discussion}

Our results show that enumeration of sexual orientation in antibullying laws at the state level was associated with fewer suicide attempts, including serious attempts requiring medical attention, compared with state statutes that do not enu- merate sexual orientation. Youth in states with enumerated statues also reported feeling safer at school or on the way to or from school, and were less likely to have been physically forced to have sexual intercourse. In considering the significant effects we found, it is important to recall that all states have antibullying laws, which provide some baseline protection. It is, thus, all the more noteworthy that even with the general antibullying laws, evidence shows an impact that is specific for enumerated statutes.

Interestingly, our results show that the effects of having sexual orientation enumeration were the same for sexual minority and non sexual minority youth. An explanation may be that actions taken along with enumeration, such as enactment of specific policies and model programs, have an impact that does not distinguish sexual minority and non sexual minority youth. Because we were limited in testing mechanisms of the associations we detected, this could not be assessed.

Thus, our findings show that while enumeration is effective in reducing suicide attempts and other stressors, it is insufficient at reducing disparities between sexual minority and non sexual minority youth in bullying, related stressors, and suicide attempts. That is, while fewer youth attempted suicide in states with enumerated statutes compared with states that do not have enumerated statutes, sexual minority youth have higher prevalence of suicide attempts than nonsexual minority youth both in states with and without enumerated statutes.

Our results are consistent with advocates' and other researchers' assertions that sexual orientation enumeration is merely a first step in addressing bullying and its ill effects. For example, Russell et al. suggested that enumeration is "a foundation on which other lesbian, gay, bisexual, transgender, and questioning (LGBTQ) safe school policies and practices can be based." 12 In addition to enumeration, the authors recommended training of teachers on effective intervention strategies, school-based support groups (e.g., GayStraight Alliances), inclusion of LGBTQ people or issues in school curricula, and improved access to information and resources. Other strategies and approaches to prevent risk of youth suicide include promoting social connectedness among youth and schools, parents/caregivers, and communities; promoting protective school environments to improve prosocial behaviors and help-seeking behavior; and teaching coping and problem-solving skills to reduce bullying, violence, and suicide risk. ${ }^{21-23}$

\section{Study limitations}

Among our study limitations are that the cross-sectional data do not allow us to test whether state enumeration of sexual orientation was the cause of the observed differences or whether other correlated state-level factors were at work. For example, states that included enumeration by sexual orientation in their laws may also have made other efforts to address bullying and to improve the social environment. Also, we cannot state that sexual orientation enumeration per se explains the results as all states that enumerate sexual orientation also enumerate other characteristics, such as race or religion.

In addition, 27 states were randomly included in the YRBS national sample; we do not know if results would have differed had other states been included. We used a 


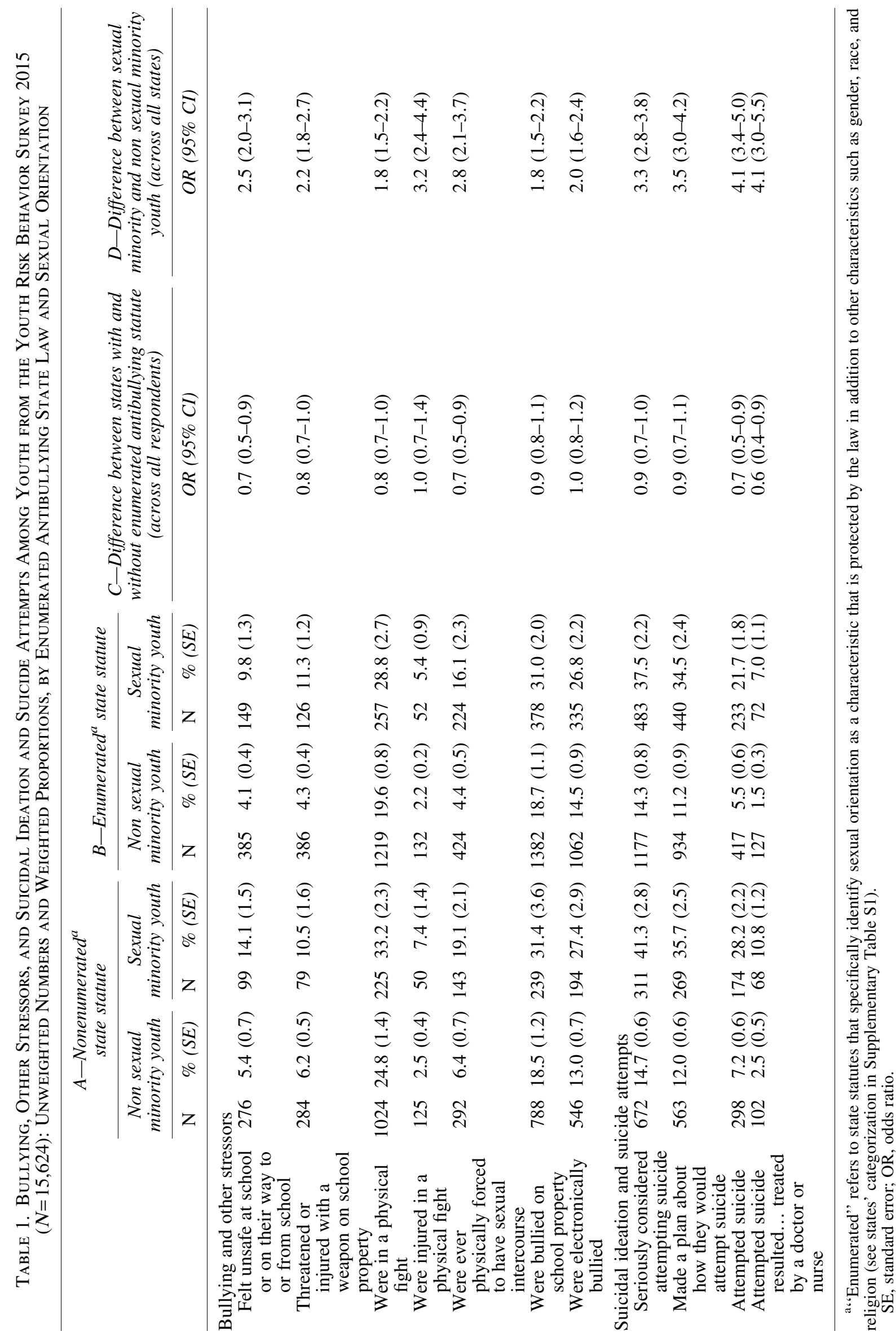


broad definition of sexual minority status but do not know if results would vary by other definitions of sexual orientation or separately for sexual minority groups (e.g., bisexual individuals). Another limitation of the study is the potential increase in error introduced by including private school student participants of the YRBS in the study. Not all states with antibullying laws require private schools to adhere to them; although some private schools adopt such state laws voluntarily, it is unclear how the voluntary adoption of regulations among private schools differs between states with and without enumerated antibullying laws. As such, the inclusion of private school participants' data likely adds misclassification error, potentially attenuating true differences between states with and without enumerated laws.

We were also limited to explore sexual orientation but not gender identity and level of conformity to conventional gender roles because, to date, YRBS has no data relevant to transgender and gender nonbinary youth. Other research has shown that gender nonconformity is strongly associated with exposure to victimization among both sexual and gender minority youth. ${ }^{15}$

\section{Conclusions}

Despite improvement in the social environment for sexual minority individuals in the United States, sexual orientation and gender identity disparities in exposure to bullying and its ill effects persist. ${ }^{24}$ The results of this analysis show that enumeration of antibullying laws by sexual orientation is associated with significant reduction in exposure to some stressful experiences and suicide attempts among all students. However, enumeration alone has not been sufficient to remove disparities based on sexual orientation in experiences of bullying and suicide attempts. Additional policies and practices to address persistent sexual orientation and gender identity disparities in exposure to bullying and suicidal behavior are promising. ${ }^{14,21}$

\section{Acknowledgments}

The authors thank Christy Mallory, JD, Maxwell Patton, and Akiesha Anderson, JD, for producing Supplementary Table S1, classifying state antibullying statutes. The authors thank Christy Mallory, JD, for her comments on an earlier version of this article.

\section{Disclaimer}

The findings and conclusions in this report are those of the authors and do not necessarily represent the official position of the Centers for Disease Control and Prevention.

\section{Author Disclosure Statement}

No competing financial interests exist.

\section{References}

1. UNESCO: Out in the Open: Education Sector Responses to Violence Based on Sexual Orientation and Gender Identity/Expression. Paris, France: United Nations Educational, Scientific and Cultural Organization, 2016.
2. Arseneault L, Bowes L, Shakoor S: Bullying victimization in youths and mental health problems: "much ado about nothing"? Psychol Med 2010;40:717-729.

3. Espelage DL, Basile KC, Hamburger ME: Bullying perpetration and subsequent sexual violence perpetration among middle school students. J Adolesc Health 2012; 50:60-65.

4. Volk A, Craig W, Boyce W, King M: Adolescent risk correlates of bullying and different types of victimization. Int J Adolesc Med Health 2006;18:575-586.

5. Jones TM, Hillier L: Sexuality education school policy for Australian GLBTIQ students. Sex Educ 2012;12:437-454.

6. Stopbullying.gov: Laws \& Policies. U.S. Department of Health and Human Services. n.d. Available at https://www.stop bullying.gov/laws/index.html, Accessed December 22, 2017.

7. Hatzenbuehler ML, Schwab-Reese L, Ranapurwala SI, et al.: Associations between antibullying policies and bullying in 25 states. JAMA Pediatr 2015;169:e152411.

8. Ramirez M, Ten Eyck P, Peek-Asa C, et al.: Evaluation of Iowa's anti-bullying law. Injury Epidemiol 2016;3:15.

9. Kann L, Olsen EO, McManus T, et al.: Sexual identity, sex of sexual contacts, and health-related behaviors among students in grades 9-12 - United States and selected sites, 2015. MMWR Surveill Summ 2016;65:1-202.

10. Eisenberg ME, Gower AL, McMorris BJ, et al.: Risk and protective factors in the lives of transgender/gender nonconforming adolescents. J Adolesc Health 2017;61:521-526.

11. Stone DM, Luo F, Ouyang L, et al.: Sexual orientation and suicide ideation, plans, attempts, and medically serious attempts: Evidence from local Youth Risk Behavior Surveys, 2001-2009. Am J Public Health 2014;104:262-271.

12. Russell ST, Kosciw JG, Horn S, Saewyc E: Safe schools policy for LGBTQ students. Soc Policy Rep 2010;24:1-25.

13. GLSEN: Enumeration. GLSEN. n.d. Available at https://www .glsen.org/sites/default/files/Enumeration_0.pdf, Accessed December 9, 2018.

14. Thoreson R: "Like Walking Through a Hailstorm" Discrimination Against LGBT Youth in US Schools. Human Rights Watch. 2016. Available at https://www.hrw.org/ report/2016/12/07/walking-through-hailstorm/discriminationagainst-lgbt-youth-us-schools\#, Accessed December 9, 2018.

15. Toomey RB, Ryan C, Diaz RM, et al.: Gendernonconforming lesbian, gay, bisexual, and transgender youth: School victimization and young adult psychosocial adjustment. Dev Psychol 2010;46:1580-1589.

16. Hatzenbuehler ML, Keyes KM: Inclusive anti-bullying policies and reduced risk of suicide attempts in lesbian and gay youth. J Adolesc Health 2013;53(1 Suppl):S21S26.

17. Meyer IH: Prejudice, social stress, and mental health in lesbian, gay, and bisexual populations: Conceptual issues and research evidence. Psychol Bull 2003;129:674-697.

18. Centers for Disease Control and Prevention: Youth Risk Behavior Surveillance System (YRBSS) Overview. 2017. Available at https://www.cdc.gov/healthyyouth/data/yrbs/ overview.htm, Accessed March 21, 2018.

19. Centers for Disease Control and Prevention: Software for Analysis of YRBS Data. Available at https://www.cdc .gov/healthyyouth/data/yrbs/pdf/2015/2015_YRBS_analysis_ software.pdf, Accessed February 7, 2017.

20. Gorrell P: Survey Analysis: Options for Missing Data. IMPAQ International, LLC. 2010. Available at https:// www.lexjansen.com/nesug/nesug10/sa/sa13.pdf, Accessed December 21, 2017. 
21. Stone DM, Holland KM, Bartholow B, et al.: Preventing Suicide: A Technical Package of Policies, Programs, and Practices. Atlanta, GA: National Center for Injury Prevention and Control, Centers for Disease Control and Prevention, 2017.

22. Burton CL, Bonanno GA, Hatzenbuehler ML: Familial social support predicts a reduced cortisol response to stress in sexual minority young adults. Psychoneuroendocrinology 2014;47:241-245.

23. Stone DM, Luo F, Lippy C, McIntosh WL: The role of social connectedness and sexual orientation in the prevention of youth suicide ideation and attempts among sexually active adolescents. Suicide Life Threat Behav 2015;45:415-430.
24. Meyer IH: The elusive promise of LGBT Equality. Am J Public Health 2016;106:1356-1358.

Address correspondence to:

Ilan H. Meyer, PhD

The Williams Institute

School of Law

University of California Los Angeles

Box 951476

Los Angeles, CA 90095-1476

E-mail: meyer@law.ucla.edu 